\title{
Consumo de suplementos e risco de distúrbios no comportamento alimentar em atletas adolescentes de Porto Alegre
}

http://dx.doi.org/10.11606/1807-5509201900010013

\author{
Luiza Laubert LA PORTA* \\ Fernanda Donner ALVES ${ }^{* *}$ \\ Carolina Guerini de SOUZA ${ }^{* * * *}$ \\ *Departamento de \\ Nutrição, Universidade \\ Federal do Rio Grande \\ do Sul, Porto Alegre, \\ RS, Brasil. \\ ${ }^{*}$ Centro Universitário \\ Ritter dos Reis, Porto \\ Alegre, RS, Brasil. \\ ${ }^{* * *}$ Centro de Estudos \\ em Alimentação e \\ Nutrição, Universidade \\ Federal do Rio Grande \\ do Sul, Porto Alegre, \\ RS, Brasil.
}

\section{Resumo}

0 objetivo do presente estudo foi avaliar o consumo de suplementos alimentares por atletas adolescentes de diferentes modalidades esportivas de um clube de Porto Alegre, o risco de distúrbios no comportamento alimentar e possiveis associações destas variáveis com o treinamento esportivo. Trata-se de um estudo transversal com 133 atletas federados praticantes de nove modalidades esportivas em que foram avaliados o consumo de suplementos alimentares, comportamento alimentar e insatisfação com a imagem corporal. A amostra foi composta por adolescentes sendo predominante o sexo masculino (57\%), com idade média de $15,8 \pm 2$ anos. Mais de $30 \%$ declarou consumir suplementos, com objetivo principal de melhorar o desempenho esportivo, sendo o carboidrato e a proteína os mais citados. Dos que consumiam 80\% tinha orientação nutricional da nutricionista do clube para este uso. Participar de modalidades esportivas individuais e praticar musculação aumentaram a probabilidade de consumo de suplementos em 6 e 15 vezes, respectivamente. A avaliação do comportamento alimentar resultou em baixo risco de distúrbio, e a insatisfação com a imagem corporal foi menor nos homens que usavam suplementos $(p=0,048)$. Portanto, a população de atletas adolescentes estudada apresentou um maior consumo de suplementos alimentares nos atletas que praticavam esportes individuais e musculação, em sua maioria, na busca de melhora de desempenho e melhora da imagem corporal. A presença de nutricionista no clube esportivo pode estar relacionada com a baixa prevalência de distúrbios do comportamento alimentar.

Palavras-chave: Esportes Juvenis; Exercício; Suplementos Nutricionais; Transtornos da Alimentação e da Ingestão de Alimentos.

\section{Introdução}

O estado nutricional e o consumo alimentar são reconhecidos como uns dos componentes chave para a melhora de desempenho esportivo ${ }^{1}$ e neste sentido, é cada vez maior a atenção ao suprimento de nutrientes adequados para atender a demanda exigida pelas modalidades esportivas ${ }^{2}$. Atletas adolescentes, em especial, devem ter cuidados alimentares, pois precisam atender tanto a demanda nutricional da fase de desenvolvimento, quanto as exigências da própria prática esportiva ${ }^{3}$. As recomendaçôes nutricionais existentes para atletas adolescentes se assemelham com as preconizadas para adultos, principalmente na distribuição de macronutrientes, e as evidências e recomendaçóes de uso de suplementos alimentares para esta faixa etária ainda são escassas ${ }^{2}$.

Suplementos alimentares ou recursos ergogênicos são produtos ou substâncias que auxiliam na melhora de desempenho físico ao aumentar a produção ou utilização de energia ${ }^{4,5}$. O consumo destes vem crescendo gradativamente, uma vez que a grande 
variedade e facilidade de acesso a esses produtos, aliados a mídia, favorece esta prática, muitas vezes sem orientação de profissional ${ }^{6}$. A busca pela rápida melhora na composição corporal e no desempenho parecem estar entre os principais motivos para uso dos mesmos ${ }^{7}$.

Outro aspecto no contexto esportivo é que a necessidade de atingir uma composiçáo corporal adequada ou específica para modalidade, aliada à preocupação que alguns já possuem com sua aparência, pode desencadear alterações no comportamento alimentar. Estas alteraçóes podem tanto relacionar-se com o desejo por perda de gordura e/ou ganho de massa muscular, quanto também pela qualidade da dieta ${ }^{8}$. Os distúrbios de comportamento alimentar em atletas podem ter origem multifatorial, seja pela carga/volume aumentado de treinamento, imposiçóes vindas do treinador para perda de peso, ou também, pela imagem corporal que a sociedade legitimiza versus a composição corporal que a categoria esportiva requer'.

\section{Método}

\section{Delineamento e amostra}

Estudo transversal com 133 atletas pertencentes a diferentes modalidades esportivas competitivas de um clube esportivo de Porto Alegre, Rio Grande do Sul. A amostra foi definida por conveniência, sendo incluídos todos os atletas do clube que tinham entre 10 a 19 anos, de ambos os sexos, federados e ativos em competiçóes durante o ano da realização do estudo. Atletas lesionados e afastados do treinamento e/ou competiçóes nos últimos 6 meses foram excluídos da amostra.

Em horários a parte aos treinos, os atletas foram abordados, informados sobre a pesquisa e convidados a participar da mesma. Aqueles que aceitaram, preencheram o Termo de Consentimento Livre e Esclarecido (TCLE) e receberam orientaçóes sobre o preenchimento dos instrumentos de coleta de dados, sendo que aos atletas menores de idade foi solicitada a assinatura do TCLE aos pais ou responsáveis. Os participantes foram orientados a responder de forma individual, estando os pesquisadores disponíveis para auxiliar, caso houvesse dúvidas. Este estudo foi submetido e aprovado pelo Comitê de Ética em Pesquisa do Hospital de Clínicas
Alguns estudos vêm sendo realizados para avaliar o perfil dos indivíduos consumidores de suplementos e sua associação com diversas variáveis, como tipo de suplemento, frequência, e outros ${ }^{10,11}$. A maioria desses estudos é realizada com adultos fisicamente ativos, praticantes de diferentes modalidades esportivas e com objetivos diversos, porém pouco se avaliam esses fatores em atletas adolescentes. Embora haja situações que justifiquem o uso dos suplementos, sabe-se que muitos atletas não buscam orientação de profissionais para avaliar a necessidade individual. Empiricamente, é sabido que técnicos, vendedores, colegas de time e familiares são os maiores responsáveis pela orientação de consumo ${ }^{4}$, entretanto, ainda são escassos na literatura dados sobre esta prática, especialmente nesta fase do ciclo da vida. Desta forma, o objetivo deste estudo foi avaliar o consumo de suplementos alimentares por atletas adolescentes de diferentes modalidades, o risco de distúrbios no comportamento alimentar e possíveis associaçóes destas variáveis com a prática do treinamento esportivo.

de Porto Alegre - RS (HCPA), sob o número 15-0493.

\section{Protocolo de avaliaçóes}

Antropometria e Prática Esportiva: peso (kg), estatura $(\mathrm{cm})$ e composição corporal (percentual de gordura corporal (\%GC)) e massa magra em kg (MM)) foram obtidos dos prontuários do clube, uma vez que a análise de composição corporal é realizada na rotina de atendimentos ambulatoriais aos atletas. Foram coletados os dados com data mais próxima da aplicaçáo do questionário, sendo utilizado o protocolo de Falkner ${ }^{12}$ para averiguaçáo do percentual de gordura e o método de Rose e Guimarães ${ }^{13}$ para estimativa de massa óssea e muscular. Sobre a prática esportiva, foi questionada a modalidade praticada, tempo de prática em anos, frequência de treino semanal, horas de treino diárias, prática de musculação e frequência semanal, especificando tempo em horas por cada sessão.

Uso de Suplementos Alimentares: o consumo de suplementos alimentares foi avaliado a partir de um instrumento elaborado pelos pesquisadores. A etapa inicial do instrumento abordava o uso atual de suplementos e, caso fizesse uso, o participante era direcionado a uma próxima etapa. Aqueles que 
consumiam, eram questionados sobre orientação para utilização, procura por nutricionista para iniciar o uso, frequência de consumo dos diversos tipos de suplemento e local de compra.

Avalição do Comportamento Alimentar (CA) e Imagem Corporal: foi utilizado o Eating Behavior Body Image Test, validado no Brasil por Galindo e CarvalHo ${ }^{14}$, que avalia tendências para desenvolvimento de distúrbios no comportamento alimentar. $O$ teste é composto por questóes que abrangem insatisfação com a imagem corporal, o comer restritivo e o comer em excesso, havendo quatro opçóes de resposta: $0=$ nunca; $1=$ raramente (uma vez por mês); 2 = frequentemente (uma vez por semana) e 3 = a maior parte do tempo (todos os dias) e tem pontuação mínima de 0 e máxima de 126 pontos. Quanto maior a pontuação, maior a tendência em desenvolver algum distúrbio no comportamento alimentar. Ainda, o questionário apresenta questóes específicas para análise de insatisfação de imagem corporal, Fator 1 (F1) e para o comer disfuncional (restrito ou em excesso), Fator 2 (F2), sendo a pontuaçáo máxima 69 e 45, respectivamente, e 0 a mínima para ambas as questóes.

\section{Resultados}

Os 133 atletas avaliados pertenciam a nove modalidades esportivas: voleibol (27\%), natação (24\%), basquete (14\%), judô (11\%), esgrima (7\%), remo $(5 \%)$, tênis $(5 \%)$, ginástica artística $(5 \%)$ e rítmica (2\%). A média de idade foi de 15,8 \pm 2 anos, sendo a maioria do sexo masculino (57\%). Os dados antropométricos e relacionados ao treinamento estáo descritos na TABELA 1.

O uso de suplementação abrangeu $38 \%$ da amostra, com uma mediana de tempo de consumo de 12 $(6-36)$ meses. $\mathrm{O}$ consumo foi significativamente maior nos homens do que nas mulheres ( $70 \%$ vs $30 \%$; $\mathrm{p}=0,04)$ e objetivo de uso principal foi melhora do desempenho (48\%), sendo também este o benefício mais citado (28\%). Dos consumidores, $80 \%$ havia recebido orientaçáo de nutricionista para o uso, sendo as fontes de indicação mais citadas o nutricionista (56\%) e treinador (24\%), seguidas de médico (6\%), indicação de várias pessoas $(6 \%)$, médico e nutricionista $(4 \%)$ e iniciativa própria $(4 \%)$. Houve diferença significativa entre os sexos no local de compra dos produtos: homens buscaram mais lojas de suplementos do que as mulheres ( $94 \%$ vs $90 \% ; \mathrm{p}=0,024)$, as quais também compravam em farmácias. Entre os suplementos

\section{Análise estatística}

Os dados foram analisados com o software IBM SPSS Statistics, versão 20.0. A distribuição das variáveis foi analisada pelo teste de KolmogorovSmirnov, sendo as variáveis contínuas descritas como média e desvio padráo ou mediana e intervalo interquartil, e as frequências descritas em números absolutos e percentuais. Foram aplicados os testes de Qui-quadrado para identificar as associações entre as variáveis categóricas, teste $t$ de Student (variáveis com distribuição normal) ou Mann-Whitney (variáveis não-paramétricas) para as comparaçóes de médias ou medianas das variáveis de composiçáo corporal, tempo de prática do exercício e pontuação dos questionários entre os grupos que usavam ou não suplementos alimentares. Além disso, foi realizada análise multivariada por Regressão de Poisson, para avaliar efeito da modalidade esportiva e prática de musculaçáo na probabilidade de consumo de suplementos. $\mathrm{O}$ valor de $\mathrm{p}<0,05$ foi adotado para significância estatística.

utilizados estavam carboidratos (maltodextrina e gel de carboidrato), proteína (whey protein e barra de proteína) e aminoácidos (aminoácidos de cadeira ramificada, creatina, glutamina e leucina), sendo que beta-alanina e suplementos termogênicos, também avaliados, não estavam sendo usados pelos atletas neste momento do estudo. A frequência de utilização dos suplementos avaliados pode ser vista na FIGURA 1.

As modalidades que mais consumiam suplementos foram natação e tênis $(60 \%$ e $12 \%)$ e das que não usavam houve uma maior predominância do vôlei e basquete $(41 \%$ e $18 \%)(\mathrm{p}<0,05)$. Nas modalidades individuais, $60,3 \%$ dos atletas consomem suplemento enquanto apenas $10,2 \%$ nas modalidades coletivas. De acordo com a análise multivariada, a probabilidade de consumo de suplementos para atletas de modalidades individuais foi seis vezes maior comparado a modalidades coletivas $(\mathrm{B}=5,92, \mathrm{p}<0,001, \beta=1,78$ ) e fazer musculaçáo aumenta esta mesma probabilidade em 15 vezes $(B=15,19, p<0,001, \beta=2,72)$.

Em relação às comparaçóes das variáveis antropométricas e relacionadas ao treinamento entre os atletas que consomem ou não suplementos, analisando a populaçáo sem divisão por sexo, o 
grupo que utilizava suplementos possuía maior estatura, menor \%GC e maior MM, além de praticarem o esporte há mais tempo (dados não mostrados). Porém, como essas diferenças poderiam estar associadas ao maior percentual de homens no grupo que consome suplementos, as variáveis foram comparadas entre os sexos que consumiam ou não (TABELA 2). Esta comparação manteve significativa a diferença de maior estatura entre os homens, o menor \%GC em ambos os sexos e o maior tempo de prática em mulheres, no grupo que usava suplementos.
$\mathrm{Na}$ avaliação do $\mathrm{CA}$, a pontuação média total do questionário foi $26(16-36)$ pontos para amostra geral e não variou significativamente entre os grupos que usam ou não suplemento (TABELA 2). As questóes específicas para análise de insatisfação de imagem corporal (F1) teve pontuação mediana na amostra total de $13(6-22)$ pontos e foi menor nos homens que usavam suplementos $(\mathrm{F} 1, \mathrm{p}=0,048$, TABELA 2). Não houve diferença entre os grupos nas questóes específicas para análise do comer disfuncional e a pontuaçáo mediana da amostra total para essa questão foi $11(6-17)$.

TABELA 1 - Características antropométricas e de prática esportiva dos atletas.

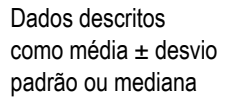

\begin{tabular}{lccc}
\hline & Todos $(\mathbf{n}=\mathbf{1 3 3})$ & Sexo masculino $(\mathbf{n}=\mathbf{7 6})$ & Sexo feminino $(\mathbf{n}=\mathbf{5 7})$ \\
\hline Idade (anos) & $15,8 \pm 2,0$ & $16,2 \pm 2$ & $15,0 \pm 1,9$ \\
Peso (kg) & $60,8 \pm 12,5$ & $64,5 \pm 12$ & $57,0 \pm 11,5$ \\
Estatura (cm) & $168 \pm 0,9$ & $173,0 \pm 0,1$ & $164,0 \pm 0,06$ \\
GC (\%) & $13,9 \pm 3,9$ & $12,0 \pm 3,0$ & $15,6 \pm 3,9$ \\
MM (kg) & $28,1 \pm 7$ & $29,7 \pm 6,3$ & $26,4 \pm 7,4$ \\
Prática esportiva (anos) & $5,5(4-10)$ & $7,0(4-10)$ & $6,0(3-9)$ \\
Treino (h/diário) & $3,0(2-3,5)$ & $3(2-4)$ & $3(3-3,5)$ \\
Musculaçáa (h/semana) & $1,28 \pm 0,36$ & $1,3 \pm 0,33$ & $1,25 \pm 0,38$ \\
Musculaçáa (d/semana) & $3 \pm 0,8$ & $3,11 \pm 0,9$ & $2,87 \pm 0,62$ \\
\hline
\end{tabular}

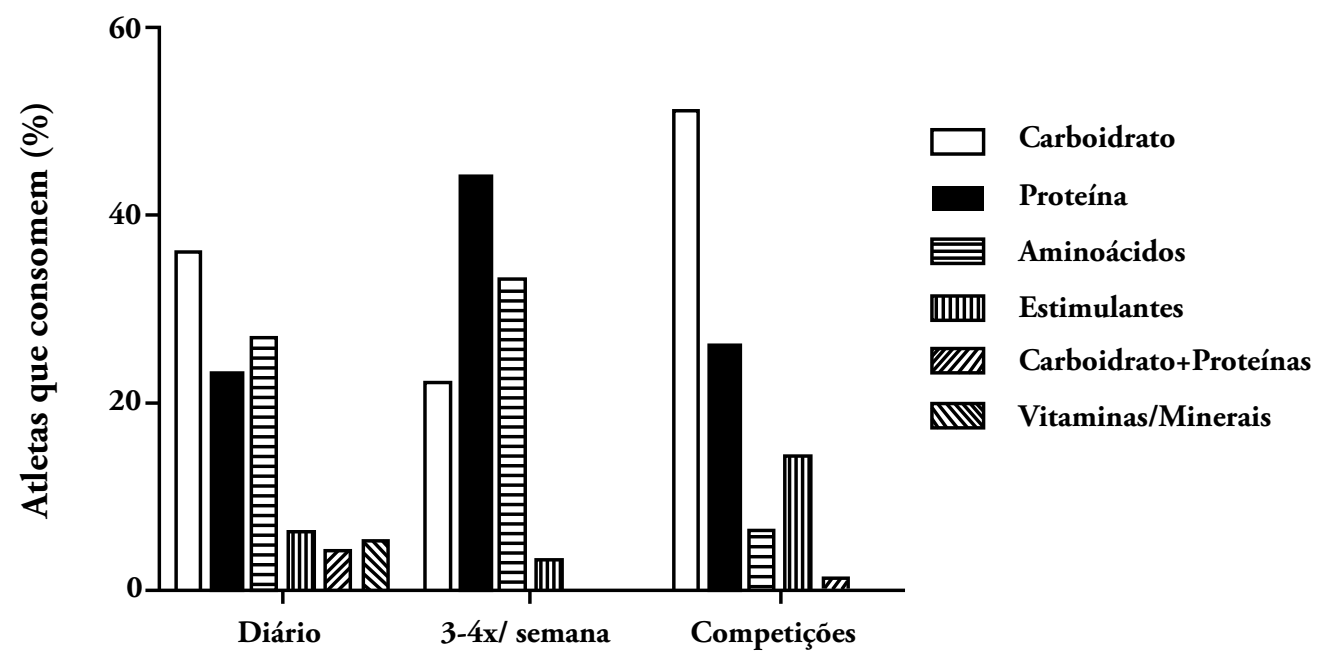

Frequência de consumo

FIGURA 1 - Percentual e frequência de consumo dos suplementos. Carboidrato: maltodextrina, géis e outros; Proteína: Whey Protein e barra de proteína; Aminoácidos: aminoácidos de cadeira ramificada (ACR), creatina, leucina e glutamina; Estimulantes: cafeína e chá verde; Carboidrato + Proteína: hipercalóricos ou Repositores com a proporção de 4:1 de carboidrato para proteína; Vitaminas/ Minerais: multivitamínicos, cálcio e ferro. 
TABELA 2 - Comparação das variáveis antropométricas, esportivas e de comportamento alimentar entre os grupos que consomem ou não suplementos.

\begin{tabular}{lcccc}
\hline & \multicolumn{2}{c}{$\begin{array}{c}\text { Usa suplemento } \\
(\mathbf{n}=\mathbf{5 0})\end{array}$} & \multicolumn{2}{c}{$\begin{array}{c}\text { Náo usa suplemento } \\
(\mathbf{n = 8 3})\end{array}$} \\
\hline & $\begin{array}{c}\text { Sexo masculino } \\
(\mathbf{n}=\mathbf{3 5})\end{array}$ & $\begin{array}{c}\text { Sexo feminino } \\
(\mathbf{n}=\mathbf{1 5})\end{array}$ & $\begin{array}{c}\text { Sexo masculino } \\
(\mathbf{n}=\mathbf{4 1})\end{array}$ & $\begin{array}{c}\text { Sexo feminino } \\
(\mathbf{n}=\mathbf{4 2})\end{array}$ \\
\hline Idade (anos) & $16,5 \pm 1,9$ & $19,5 \pm 1,9$ & $16,0 \pm 2,0$ & $15,0 \pm 2,0$ \\
Peso (kg) & $65 \pm 11$ & $55 \pm 9$ & $63 \pm 13$ & $57 \pm 12$ \\
Estatura (cm) & $176 \pm 0,09^{*}$ & $163 \pm 0,04$ & $168 \pm 0,1$ & $164 \pm 0,07$ \\
Gordura corporal (\%) & $11 \pm 1,8^{*}$ & $13 \pm 1,5^{*}$ & $14 \pm 4$ & $16 \pm 4$ \\
Massa magra (kg) & $31 \pm 6$ & $28 \pm 7$ & $28 \pm 6$ & $26 \pm 7$ \\
Tempo prática (anos) & $7 \pm 4$ & $8 \pm 4^{*}$ & $6 \pm 3$ & $5 \pm 3$ \\
Tempo treino (horas/d) & $3 \pm 1$ & $3 \pm 1$ & $3 \pm 1$ & $3 \pm 0,8$ \\
Avaliaçáo do CA (pontos) & $20(12-32)$ & $21(12-47)$ & $26(16-34)$ & $32(21-53)$ \\
F1 (pontos) & $10(4-16)^{*}$ & $9(4-29)$ & $14(8-20)$ & $19(8-36)$ \\
F2 (pontos) & $12(7-16)$ & $11(7-14)$ & $10(6-16)$ & $11(6-22)$ \\
\hline
\end{tabular}

Dados descritos como média e desvio padrão analisados por teste t de Student; e dados descritos como mediana e intervalo interquartil analisados por teste Mann-Whitney. CA: questionário de comportamento alimentar; F1: pontuação do questionário relacionada à insatisfação com a imagem corporal; F2: pontuação do questionário relacionada ao comer disfuncional. *diferença significativa entre os grupos, dentro do mesmo sexo.

\section{Discussão}

Os dados sobre uso de suplementos por atletas adolescentes de diferentes modalidades esportivas indicaram um consumo em mais de $30 \%$ da amostra avaliada, sendo a maior parte destes do sexo masculino, que buscavam melhora do desempenho como principal objetivo e benefício de uso. Além disso, a insatisfação corporal foi menor nos atletas masculinos que fazem uso de suplementos, porém não houve associação entre o uso de suplementos e risco de distúrbios no comportamento alimentar.

$\mathrm{Na}$ população estudada, as modalidades que mais consumiram suplementos foram a natação e o tênis, de acordo com os achados que esportes individuais e a prática de musculação estão associadas com maior consumo. Suplementos proteicos e de carboidrato foram os mais utilizados e, dentre os que fazem uso de suplementos em geral, houve uma predominância de maior estatura, menor percentual de GC e maior tempo de prática esportiva.

O consumo de suplementos encontrado neste estudo é menor que o de FraCzeK et al..$^{15}$, onde $48,2 \%$ $(\mathrm{n}=600)$ dos atletas adultos de diversas modalidades utilizavam e também que de SousA et al. ${ }^{16}$ no qual 64\% $(\mathrm{n}=244)$ dos atletas de diversas modalidades consumiam, porém maior que DieHl et al. ${ }^{17}$, que encontrou 26,8\% ( $n=1066)$ de consumo diário pelos atletas adolescentes alemães de diversas modalidades. Certamente o tamanho amostral dos estudos também influencia estas diferenças, mas de qualquer forma, observa-se que o consumo desses produtos é bastante elevado, embora as principais recomendaçóes nutricionais para adolescentes atletas não estimulem esta prática ${ }^{2}$.

Foi observado que atletas masculinos consomem mais suplemento que femininas, o que corrobora os achados de Giannopoulou et al. ${ }^{7}$ em um estudo com atletas gregos de diversas modalidades. Isso pode ser devido ao fato de que atletas masculinos consomem tais produtos visando a melhora no desempenho esportivo, enquanto atletas femininas buscam benefícios em saúde sendo, portanto, um consumo mais comedido, sem objetivos esportivos específicos ${ }^{7}$.

Na nossa população avaliada, a maioria dos atletas tiveram orientação profissional capacitada para consumo desses produtos, devendo-se à presença de nutricionista como parte fixa da equipe multiprofissional desse clube específico, proporcionando atuação direta nas equipes esportivas. Outros autores demonstraram resultados diferentes, como DAsCOMBE et al. ${ }^{18}$ que avaliaram 63 atletas de modalidades distintas de um instituto esportivo, e esses priorizavam agentes de saúde em geral (psicólogos, nutricionista e médicos) para orientação de consumo; e DieHl et al. ${ }^{17}$, constataram que os atletas buscavam primeiro o treinador, depois o preparador físico e em terceiro caso o nutricionista. De acordo com a Lei no 8.234/1991 vigente no Brasil que regulamenta 
a profissão de nutricionista, a prescrição de suplementos alimentares é atribuição específica dessa categoria, não sendo recomendada à outras profissóes. Porém, devido a facilidade de acesso a esses produtos e a falta de fiscalização, a prescrição de suplementos acontece por profissionais de diversas áreas.

A natação e o tênis foram as modalidades com maior consumo de suplementos, o que pode ser relacionado ao fato de serem esportes individuais, com alto nível de treinamento e competitividade. SHAw et al. ${ }^{19}$ afirmam que nadadores competitivos são consumidores entusiastas desses produtos, uma vez que a periodização do treinamento aliado às competições requerem um plano alimentar especial que garanta a recuperação entre os eventos. De forma semelhante, o tênis, que além de apresentar um cronograma anual de treinos e competiçôes intenso, conta também com a irregularidade na duraçáo e intervalo entre as partidas. Sendo assim, o atleta requer uma adequada ingestão de nutrientes para garantir a recuperaçáo e manter o nível de desempenho ${ }^{20}$. É importante levar em consideração também que essas modalidades esportivas quando comparadas às outras, possuem um maior investimento financeiro e alta visibilidade de mídia, o que pode promover interesse comercial de patrocinadores do mercado da suplementação, atuando diretamente fornecendo produtos aos atletas. Complementarmente, identificamos que nos esportes individuais houve quase 6 vezes mais probabilidade de consumo de suplementos alimentares do que em esportes coletivos. De forma semelhante, Giannopoulou et al. ${ }^{7}$ encontrou um maior consumo de suplementos por parte de atletas que pertenciam a modalidades individuais (44\%) quando comparado com atletas de times esportivos (35\%). Esses dados sugerem que atletas de modalidades individuais têm maior interesse em buscar meios de melhorar o desempenho no esporte que pratica quando comparado com atletas participantes de times ou equipes.

Os suplementos mais consumidos diariamente foram os de carboidratos, seguido pelos de proteínas ou aminoácidos. Diferentemente, SATO et al. ${ }^{21}$ encontraram uma maior utilização de aminoácidos ou proteínas em atletas adolescentes. Ainda, em um estudo que avaliou o consumo de medicamentos e suplementos de jogadores de futsal brasileiros em quatro edições de Copa do Mundo de Futsal, foram apresentados um maior consumo de vitaminas, minerais e aminoácidos ${ }^{22}$, bem como resultados semelhantes encontrados por $\mathrm{GACEK}^{23}$. Embora exista uma grande variedade de suplementos à disposição dos atletas, existe um padrão de consumo entre alguns principais, como proteína e carboidratos.
Possivelmente isso se deve ao fato de que estes são os mais utilizados para atender as demandas energéticas envolvidas no treinamento, a qual nem sempre consegue ser suprida apenas com alimentos, devido ao alto volume que pode representar para ingestáo ${ }^{24}$. Ainda, algumas modalidades apresentam um padrão de consumo de suplemento, como aquelas praticadas ao ar livre ou que acarretam grandes perdas de eletrólitos no suor, favorecendo a reposiçáo destes por meio de suplementos minerais ou bebidas esportivas ${ }^{25}$.

Dos suplementos consumidos de três a quatro vezes por semana, foram mais utilizados os derivados de proteína e aminoácidos, fato que foi associado com a prática de musculação. É fato também que o consumo de suplementos proteicos, especialmente whey protein, é bastante disseminado pelo aumento de força e hipertrofia cientificamente atribuídos a estes $^{25}$. Da mesma forma, ao aumentar força e massa muscular, aumentam-se as probabilidades de melhora no desempenho ${ }^{26}$, sendo este o principal motivo de uso e benefício citado pelos atletas.

Os resultados da pontuaçáo total do questionário de CA não tiveram relaçáo significativa com consumo de suplemento, uma vez que houve baixa pontuação no mesmo, podendo indicar que para essa população existe uma baixa propensão ao desenvolvimento de distúrbio no comportamento alimentar. Os achados da pesquisa de Fortes et al. ${ }^{27}$ váo de encontro aos do presente estudo, uma vez que ao avaliar a propensão para distúrbios alimentares com o auxílio da ferramenta Eating Attitudes Test (EAT 26) entre atletas e não atletas brasileiros, foi encontrada baixa prevalência em atletas. Ainda, Prather et al. ${ }^{28}$ também encontrou baixa propensão à distúrbios alimentares ao avaliar jogadoras de futebol de um clube profissional. As questóes específicas de insatisfação com a imagem corporal e comer disfuncional também obtiveram baixa pontuação geral, entretanto o uso de suplementos no sexo masculino foi associado com menor insatisfação com a imagem corporal. De qualquer forma, não é possível fazer relaçôes de causa e efeito por tratar-se de um estudo transversal, sendo necessários estudos de acompanhamento para que se possam tirar conclusóes robustas. Embora o instrumento utilizado avalie apenas risco para alteraçóes no comportamento alimentar, a baixa pontuação obtida foi tida como positiva, uma vez que para essa populaçáo existe a necessidade e a cobrança de uma composiçáo corporal adequada e isso muitas vezes pode prejudicar o atleta por facilitar comportamentos alimentares disfuncionais ${ }^{9}$. Ainda, a presença fixa de profissionais de nutrição e psicologia no clube podem favorecer a baixa propensão a desenvolver 
algum distúrbio alimentar, e isso se deve ao ambiente que esses profissionais propiciam dentro do clube.

Algumas limitaçóes deste estudo devem ser levadas em consideração na interpretação e extrapolação dos resultados, tais como a heterogeneidade de modalidades esportivas, que trazem consigo a variabilidade de perfis dos atletas e o tamanho amostral reduzido em algumas modalidades, inviabilizando um comparativo entre as mesmas.
Como conclusão, a população de atletas adolescentes estudada apresentou um maior consumo de suplementos alimentares nos atletas que praticavam esportes individuais e musculação, em sua maioria, na busca de melhora de desempenho e melhora da imagem corporal. A presença de nutricionista no clube esportivo pode estar relacionada com a baixa prevalência de distúrbios do comportamento alimentar.

\section{Abstract}

Dietary supplements consumption and risk of eating disorders in teenagers athletes from Porto Alegre

The aim of study was evaluate the consumption of dietary supplements by teenagers athletes of different sports, the risk of eating disorders and possible associations of these variables with training. This were a cross-sectional study with 133 athletes of nine sports. The consumption of dietary supplements and related factors, eating behavior and body image dissatisfaction were evaluated with specific questionnaires. The sample consisted mainly by male teenagers (57\%) with age of $15.8 \pm 2.0$ years olds. More than $30 \%$ of the sample consumed supplement and performance improvement was the main goal of consumption, being carbohydrate and protein were the most used supplements. From this 30\% who consumed, 80\% had nutritional counseling for this use. Participate of individual sports and practice resistance training increased the likelihood of consumption by 6 and 15 times, respectively. Athletes who use supplements had lower percentage of body fat, in both sexes. The evaluation of the eating behavior resulted in low risk of disorders, however dissatisfaction with body image was lower in men who used supplements $(p=0.048)$. Therefore, this sample presented high percentage of dietary supplements consumption in athletes of individual sports and in those who also practiced resistance training, with main goal of performance and body image improvement. The presence of nutritional counseling in the sports club may be related to low risk of eating disorders.

KEYWORDS: Youth Sports; Exercise; Dietary Supplements; Feeding and Eating Disorders.

\section{Agradecimentos}

Os autores agradecem o financiamento do Fundo de Incentivo à Pesquisa e Eventos, Hospital de Clínicas de Porto Alegre (FIPE/HCPA) e ao Grêmio Náutico União de Porto Alegre.

\section{Referências}

1. Beck KL, Thomson JS, Swift RJ, von Hurst PR. Role of nutrition in performance enhancement and postexercise recovery. J Sports Med. 2015;6:259-67.

2. Desbrow B, McCormack J, Burke EM, et al. Sports dietitians Australia position statement: sports nutrition for the adolescent athlete. Int J Sport Nutr Exerc Metab. 2014;24(5):570-84.

3. Galanti G, Stefani L, Scacciati I, Mascherini G, Buti G, Maffulli, N. Eating and nutrition habits in young competitive athletes: a comparison between soccer players and cyclists. Transl Med UniSa. 2014;11:44-7.

4. Thomas DT, Erdman KA, Burke LM. American College Sports Medicine Joint Position Statement. Nutrition and Athletic Performance. Med Sci Sports Exerc. 2016;48(3):543-68. 
La Porta LL, et al.

5. Brasil. Ministério da Saúde. Resolução RDC no 18, de 27 de abril de 2010: dispóe sobre alimentos para atletas. Diário Oficial da União [Internet]. 28 abr 2010 [citado 12 maio 2015]. Disponível em: http://portal.anvisa.gov.br/documents/10181/2718376/ RDC_18_2010_COMP.pdf/1f6elbaf-fd83-4408-8e97-07578fe3db18.

6. Mason BC, Lavallee ME. Emerging supplements in sports. Sports Health. 2012;4(2):142-6.

7. Giannopoulou I, Noutsos K, Apostolidis N, Bayios I, Nassis GP. Performance level affects the dietary supplement intake of both individual and team sports athletes. J Sports Sci Med. 2013;12(1):190-6.

8. Torstveit MK, Aagedal-Mortensen K, Stea TH. More than half of high school students report disordered eating: A cross sectional study among Norwegian boys and girls. PLoS ONE. 2015;10(3):e0122681.

9. Giel KE, Hermann-Werner A, Mayer J, et al. Eating Disorder Pathology in Elite Adolescent Athletes. Int J Eat Disord. 2016;49(6):553-62.

10. Fayh AP, Silva CV, Jesus FR, Costa GK. Consumo de suplementos nutricionais por frequentadores de academias da cidade de Porto Alegre. Rev Bras Ciên Esporte. 2013;35(1):27-37.

11. Santos DA, Dawson JA, Matias CN, et al. Reference values for body composition and anthropometric measurements in athletes. PLoS ONE. 2014;9(5):e-97846.

12. Faulkner JA. Physiology of swimming and diving. In: Falls H. Exercise physiology. Baltimore: Academic Press; 1968. p. $415-46$.

13. Rose EH, Pigatto E, Rose RCF. Cineantropometria, educação física e treinamento desportivo. Rio de Janeiro: FAE; 1984.

14. Galindo EMC, Carvalho AMP. Tradução, adaptação e avaliação da consistência interna do Eating Behaviours and Body Image Test para uso com crianças do sexo feminino. Rev Nutr. 2007;20(1):47-54.

15. Fraczek B, Warzecha M, Tyrala F, Pieta A. Prevalence of the use of effective ergogenic aids among professional athletes. Rocz Panstw Zakl Hig. 2016;67(3):271-8.

16. Sousa M, Fernandes MJ, Carvalho P, Soares J, Moreira P, Teixeira VH. Nutritional supplements use in high-performance athletes is related with lower nutritional inadequacy from food. J Sport Health Sci. 2015;5(3):368-74.

17. Diehl K, Thiel A, Zipfel S, Mayer J, Schnell A, Schneider S. Elite adolescent athletes use of dietary supplements: characteristics, opinions , and sources of supply and information. Int J Sport Nutr Exerc Metab. 2012;22(3):165-74.

18. Dascombe BJ, Karunaratna M, Cartoon J, Fergie B, Goodman C. Nutritional supplementation habits and perceptions of elite athletes within a state-based sporting institute. J Sci Med Sport. 2010;13(2):274-80.

19. Shaw G, Boyd KT, Burke LM, Koivisto A. Nutrition for swimming. Int J Sport Nutr Exer Metab. 2014;24(4):360-72.

20. Ranchordas MK, Rogersion D, Ruddock A, Killer SC, Winter EM. Nutrition for tennis: practical recommendations. J Sports Sci Med. 2013;12(2):211-24.

21. Sato A, Kamei A, Kamihigashi E, et al. Use of supplements by young elite japanese athletes participating in the 2010 Youth Olympic Games in Singapore. Clin J Sport Med. 2012;22(5):418-23.

22. Pedrinelli A, Ejnisman L, Fagotti L, Dvorak J, Tscholl PM. Medications and Nutritional Supplements in Athletes during the 2000, 2004, 2008, and 2012 FIFA Futsal World Cups. Biomed Res Int [Internet]. 2015 [citado 25 jul 2019]:870308. Disponível em: https://leandroejnisman.com.br/wp-content/uploads/2018/12/futsal-ortopedia.pdf.

23. Gacek M. Association between general self-efficacy level and use of dietary supplements in the group of american football players. Rocz Panstw Zakl Hig. 2016;67(1):31-6.

24. Mielgo-Ayuso J, Maroto-Sánchez B, Luzardo-Socorro R, Palacios G, Palacios Gil-Antuñano N, González-Gross M. Evaluation of nutritional status and energy expenditure in athletes. Nutr Hosp. 2015;31(suppl 3):227-36.

25. Bianco A, Mammina C, Thomas E, et al. Protein supplements consumption: a comparative study between the city centre and the suburbs of Palermo, Italy. BMC Sports Sci Med Rehabil. 2014;6:29.

26. van Loon LJ. Is there a need for protein ingestion during exercise? Sports Med. 2014;44(suppl 1):S105-11.

27. Fortes LS, Kakeshita IS, Almeida SS, Gomes AR, Ferreira ME. Eating behaviours in youths: a comparison between female and male athletes and non-athletes. Scand J Med Sci Sports. 2014;24(1):e62-8.

28. Prather H, Hunt D, McKeon K, et al. Are elite female soccer athletes at risk for disordered eating attitudes, menstrual dysfunction, and stress fractures? PM R. 2016;8(3):208-13.

ENDEREÇO

Carolina Guerini de Souza

Rua Ramiro Barcelos, 2400 - $4^{\circ}$ andar - 90035-003

Santa Cecília - Porto Alegre - RS - BRASIL

e-mail: carolina.guerini@ufrgs.br
Recebido para publicação: 18/04/2017

Revisão: 26/07/2017

Aceito: 18/09/2017 